\title{
A QUESTÃO AGRÁRIA BRASILEIRA NA CONSTITUINTE DE 1987 EM TORNO DO CONCEITO DE PROPRIEDADE
}

\author{
http://dx.doi.org/10.21527/2176-6622.2018.50.115-127
}

Recebido em: 25/9/2017

Aceito em: 22/10/2018

\section{Gretha Leite Maia}

Professora-adjunta lotada no Departamento de Direito Processual da Faculdade de Direito da Universidade Federal do Ceará. grethaleitemaia@gmail.com

Alaíde Linhares

Graduada em Direito pela Universidade Federal do Ceará. grethaleitemaia@gmail.com

\section{RESUMO}

Trata-se de estudo que analisa o conceito de propriedade como elemento constituído por uma mentalidade. Adota como referencial teórico o estudo de Paolo Grossi sobre a propriedade e as propriedades e seu significado para o historiador do Direito. Investiga, a partir de reconsiderações teóricas, a construção de uma mentalidade sobre a propriedade no Brasil. Como recorte empírico, analisa os trabalhos constituintes de 1987 referentes à reforma agrária no Brasil, tendo por principal referência as narrativas de José Gomes da Silva. Conclui que a inserção da função social da propriedade tem alcance muito limitado diante da inexistência de uma nova mentalidade jurídica sobre a propriedade agrária no Brasil.

Palavras-chave: Constituinte. Propriedade. Reforma agrária.

\section{THE AGRARIAN REFORM IN BRAZIL IN THE CONSTITUTIONAL ASSEMBLY IN 1987 AND THE CONCEPT OF PROPERTY}

\section{ABSTRACT}

The article aims to analyze the concept of ownership as a mentality. It adopts a theoretical study of Paolo Grossi on the property and the properties and its significance for the historian of law. It investigates how a mentality of property was done in Brazil. As empirical object, it analyzes the Constitutional Assembly of 1987 relating to Agrarian reform in Brazil, based in José Gomes da Silva narratives. It concludes that the inclusion of the social function of property in the Constitution of 1988 has a very limited reach considering the absence of a new legal mentality of ownership in Brazil.

Keywords: Constitutional assembly. Right of ownership. Agrarian reform.

\section{SUMÁRIO}

1 Introdução. 2 A Propriedade na Perspectiva da História do Direito. 30 Direito de Propriedade no Brasil e o Contexto da Constituinte de 87. 40 Resgate Histórico das Discussões sobre a Propriedade e a Reforma Agrária na Constituinte de 86/87. 5 Conclusão. 6 Referências. 


\section{INTRODUÇÃO}

Este texto tem o intuito de ser um trabalho em torno de um conceito. A formação, a construção de um conceito, e não de outro, no processo de naturalização que induz ao não questionamento e à aceitação sem reservas. Um conceito para determinar uma estrutura de proteção a partir do conteúdo dessa concepção. Um conceito para a formação de uma mentalidade que determina um comportamento com relação à propriedade no Brasil e a partir do qual se fornece uma justificação teórica para uma rede de proteção jurídica. Parte da afirmação teórica de que o regime de propriedade de uma determinada sociedade é expressão fiel de uma mentalidade. Daí sua inscrição no campo histórico.

Decorrente de um encadeamento histórico-jurídico-econômico de fatores que ocorreram no cenário europeu, especialmente em Portugal, e que chegaram ao Brasil com as grandes navegações, tem-se a concentração da propriedade agrária como uma característica estrutural que se perpetua desde o Brasil Colônia. A configuração do modelo fundiário brasileiro não é conjuntural, mas resultado de uma específica concepção sobre a posse e a propriedade da terra. A estruturação de um modelo de propriedade também não se constrói de forma instantânea, mas se faz em um lento caminho histórico, de sucessivos desafios e reafirmações dessa concepção. No caso brasileiro, é possível afirmar a construção de uma mentalidade moderna sobre a propriedade, segundo a distinção que faz Paolo Grossi entre propriedade medieval e propriedade moderna, elaborada a partir de uma investigação da história agrária europeia e mais especificamente da italiana.

Feita a análise da proposta teórica de Grossi, buscou-se traçar um panorama da afirmação do direito de propriedade, especialmente a propriedade de terras, no Brasil, por meio de uma investigação no modelo jurídico instalado por Portugal e perpetuado em seu significado desde então. Ao final, recortou-se um campo de investigação no qual as hipóteses levantadas pudessem ser verificadas. Por tratar-se de pesquisa historiográfica, o estudo tomou por objeto os debates constituintes de 1987, no passar de três décadas de sua instalação, a partir das narrativas de José Gomes da Silva sobre os debates na Constituinte em torno da reforma agrária. A pergunta de partida desta pesquisa é: Em que medida, no limiar do século 21, a questão agrária ainda permanece insolúvel, no Brasil, em razão da permanência de uma concepção específica de propriedade?

Considerando que a construção histórica e jurídica do direito de propriedade atravessa a modernidade a partir do jusnaturalismo do século 18 até alcançar a noção da função social da propriedade, este trabalho questiona as possibilidades de uma ruptura nesse padrão de compreensão e em que medida a definição constitucional de uma função social da propriedade pode ser absorvida na mentalidade da sociedade brasileira. A reconfiguração do direito de propriedade no plano normativo-constitucional é o produto atual, não final, de um dos debates mais permanentes e inconclusos na história jurídica do Brasil. Desde a Constituinte de 1823, a questão de um modelo agrário é lócus privilegiado de verificação das disputas, fraturas e divergências da sociedade brasileira. Em vários momentos históricos fez parte da pauta de discussões, como no longo processo de emancipação da mão de obra escrava durante o século 19. O objetivo do estudo é fazer, por meio de uma análise histórico-jurídica da Constituinte de 86/87, a partir das discussões que ocorreram há quase 30 anos, uma demonstração das limitações da CF/88 na tentativa de estabelecer outro modelo de distribuição e uso de terras no Brasil.

A investigação desvelou também como se deu a manutenção de um modelo por meio de discursos e enfrentamentos que demonstraram que, mais uma vez, na História brasileira, prevaleceu o autoritarismo e o conservadorismo dos grandes proprietários de terra agrária no Brasil, instrumentalizada em táticas de instalar a desordem e um clima de ameaça e intimidação com que muitas vezes os trabalhos da Constituinte foram realizados. A pesquisa é teórica e bibliográfica, com base em estudos publicados ao tempo da Constituinte que agora se resgatam.

\section{A PROPRIEDADE NA PERSPECTIVA DA HISTÓRIA DO DIREITO}

Martins (1999, p. 98, destacado pelo autor), ao analisar o primeiro governo de Fernando Henrique Cardoso, afirma que a questão agrária tem sua própria temporalidade, que não é o "tempo" de um governo; ela não é, igualmente, uma questão monolítica e invariante, uma vez que "em diferentes sociedades surge em circunstâncias históricas determinadas e passa a integrar o elenco de contradições, dilemas e tensões que mediatizam a dinâmica social e, nela, a dinâmica política." A questão é, portanto, uma questão histórica. A Histó- 
ria estuda o Direito a partir dos fatores que condicionaram suas formas, do que lhe dá contorno e conteúdo. A História passa, ela mesma, por uma refundação pela Escola dos Annales, reconfigurando seu discurso a partir da compreensão da história de longue duree (história de longa duração ou História total). Como método, a historiografia contribuiu para que o discurso jurídico se afastasse das teorias baseadas em normas transcendentes e naturais, com referência a valores eternos e imutáveis. É essa a perspectiva histórica de construção de um conceito ou de formação das mentalidades que inspira este trabalho, a partir das lições de Paolo Grossi.

Grossi perfila-se aos pensadores que estão em busca de uma outra Idade Média, conforme proposto por Le Goff (2014). Grossi (2006) investiga a história agrária europeia na busca de um conceito para a propriedade em uma Europa transformada pelo feudalismo. Trata-se, portanto, de um estudo sobre a propriedade medieval, que para o autor era plural. Daí iniciar suas reflexões a partir da proposta de uma reconsideração teórica da propriedade e das propriedades, verificando qual o seu significado para o historiador do Direito. É comum que a busca por uma renovação conceitual da propriedade inicie a investigação nas raízes da civilística de matriz romana, mas Grossi procura na relação entre os homens e as coisas na Europa Medieval o fundamento para uma certa concepção de domínio. Para ele, essas relações mostram que se exigiam diversas e peculiares construções jurídicas, gerando a ideia de múltiplas propriedades, cada uma delas tendo uma fundação estrutural.

Na condição de objeto de pesquisa do historiador do Direito, propriedade deve ser somente "o artifício verbal para indicar a solução histórica que um ordenamento dá ao problema da relação jurídica mais intensa entre um sujeito e um bem, ou, em outras palavras, a resposta à questão central sobre a consistência mínima do 'meu' jurídico" (GROSSI, 2006, p. 5). Assim considerada, somente com ênfase no individualismo possessivo, a propriedade sempre se converteria em um mínimo de pertencimento, de poderes exclusivos e dispositivos conferidos a um determinado sujeito pela ordem jurídica. Para Grossi, aí está o eixo da história jurídica da Europa Ocidental, vivida como vicissitudes de "proprietários" e luta pela "propriedade", e aí reside sua limitação. Segundo o autor, as civilizações asiáticas, africanas e americanas são uma demonstração de que esse "princípio fundador" não é necessariamente natural, mas, sobretudo, histórico e, neste contexto, a ideia de apropriação individual pode parecer apenas uma invenção.

Uma oficialidade dominante a partir da modernidade teria sepultado uma série de realidades medievais que conseguem, não obstante hostilidades e condenações, "arrastar-se intactas até nós, formas primordiais de organização comunitária de uma terra, nas quais não é somente o espírito individualista que falta, mas até mesmo o próprio espírito proprietário" (GROSSI, 2006, p. 7). A que oficialidade dominante refere-se Grossi? Historiador medievalista consagrado, Fustel de Coulanges elaborou certa compreensão da propriedade a partir de seus estudos sobre a cidade antiga, na qual a noção de propriedade teria se consolidado naturalmente em decorrência das práticas de culto aos mortos, oferecendo uma solução histórica que será revigorada também por Locke para a propriedade moderna. Como propriedade é tratada neste estudo é, sobretudo, mentalidade, pode-se afirmar que houve uma história proprietária a partir destes dois referenciais teóricos.

Segundo Coulanges (2002), o solo era sagrado para os povos primitivos da Europa porque era sede de forças sobrenaturais, uma vez que nele se encontravam os restos mortais dos antepassados, os deuses protetores do lar. Assim, a religião das sociedades primitivas europeias, que de certa forma era o modo como o homem pensava o mundo ao seu redor, determinava a relação do homem com as coisas e, consequentemente, o estabelecimento das relações de poder. Embora algumas raças jamais tenham instituído a propriedade privada da terra, como os povos tártaros que admitiam o direito de propriedade sobre os rebanhos, mas não compreendiam a propriedade do solo, nas sociedades arcaicas da Grécia a religião doméstica, a família e o direito de propriedade estavam consolidados e eram, de certa forma, inseparáveis. Assim, o lar, altar e símbolo da vida sedentária, ao ser construído sobre a terra, torna-se a morada permanente dos deuses, e não devia mais a família mudar de lugar. Nesse contexto, o lar toma posse da terra e, consequentemente, a terra torna-se propriedade da família, visto que esta, que por religião deve estar sempre agrupada ao redor do altar que estabeleceu, fixa-se ao solo com o próprio altar, dando origem à ideia de domicílio natural.

O lar, portanto, recinto sagrado chamado de érkos pelos gregos, possui a proteção dos deuses, com epíteto de erkéios, não podendo um estranho ultrapassar a linha divisória traçada pela religião para o seu culto (COULANGES, 2002). Essa concepção consolidou uma noção de propriedade/interdição. Reforçando a ideia de um modelo dominante, Maciel (2007) observa que quando Sólon, entre 594 e 593 a.C e sob influência egípcia, criou o novo Código de Leis que alterou as Leis de Drácon, de 621 a.C, e suprimiu a propriedade coletiva dos 
clãs, não havia mais resíduos do tempo em que a terra era comum. Assim, foi possível afirmar, com base nestas explicações, que, na maior parte das sociedades primitivas europeias, foi pela religião que se estabeleceu o direito de propriedade. Mesmo no Direito hebraico, que pode ser visto como um Direito fundado sob uma religião monoteísta e não politeísta, como as predominantes na Antiguidade, há um Deus proprietário primitivo por direito de criação, delegando aos homens sua propriedade sobre uma parte do solo, semelhante à civilização grega.

Os romanos, por sua vez, elaboraram a sofisticada distinção entre posse e propriedade, numa tentativa de ampliar a gramática jurídica para alcançar as múltiplas relações que se estabeleciam entre os Homens e as coisas, sublinhando a relatividade do instituto propriedade. A elaboração jurídica do direito de propriedade dos romanos influenciou de tal forma o Direito ocidental que é comum a afirmação, entre os civilistas, de que o Direito Romano elaborou a teoria da propriedade que se mantém contemporaneamente, com pequenas alterações. Com as invasões bárbaras ao Império Romano, houve a fragmentação da propriedade, dando origem aos feudos e ao regime feudal no qual vicejam novas formas de relacionamento entre o homem e a terra. Essa passagem é fundamental para a proposta de Grossi, que busca alcançar as nuances de uma propriedade moderna a partir das transformações impostas à propriedade medieval.

Ainda na trilha do discurso oficial sobre a história da propriedade, de acordo com Kelly (2010), na Alta Idade Média, na consolidação do cristianismo, não há nenhuma teoria jurídica mais elaborada sobre a propriedade. Isto porque esse cristianismo defendia que, no estado primitivo do mundo, todas as coisas pertenciam a todos os humanos e foi somente pela atuação das leis humanas que os proprietários adquiriram direito de propriedade sobre pedaços de terra. Na Baixa Idade Média a Filosofia de São Tomás de Aquino invoca o esforço produtivo para justificar a propriedade, conforme Kelly (2010). Tal concepção apoiará a tese da legitimidade de defesa e resistência diante da expropriação arbitrária.

No século 17, Locke relacionou o direito à propriedade ao trabalho, que, por sua vez, passa a ocupar lugar diferente como atividade humana na modernidade industrial. Para o filósofo, a propriedade é um direito natural e deriva diretamente do trabalho humano, constituindo este um elemento legitimador da propriedade (LOCKE, 2005). Locke defende também que deve haver limites para essa apropriação natural, somente mostrando-se legítima quando houver abundância. Caso contrário, não deve ser considerada a propriedade natural, e as regras tornam-se necessárias. O pensamento de Locke consiste numa narrativa fundadora para a modernidade, e deve ser considerada sob esta perspectiva, uma vez que não se trata de um estudo com pretensões historiográficas ou antropológicas, mas, sobretudo, filosóficas.

É necessário fazer menção ao pensamento de Rousseau como um ponto fora da curva do discurso legitimador da propriedade moderna. Rousseau (2006, p. 61), no século 18, contribui para questionar a concepção moderna ou naturalista da instituição da propriedade ao afirmar em seu Discurso sobre a origem e os fundamentos da desigualdade entre os homens que "o primeiro que tenha cercado um terreno se lembrou de dizer 'Isto é meu', e encontrou pessoas bastante simples para o acreditar, foi o verdadeiro fundador da sociedade civil". O célebre trecho prossegue: "Quantos crimes, guerras, assassínios, misérias e horrores não teria poupado ao gênero humano se aquele, arrancando as estacas ou tapando os buracos, tivesse gritado aos seus semelhantes: Livrai-vos de escutar esse impostor; estarei perdido se esquecerdes que os frutos são de todos, e a terra de ninguém".

Todos esses discursos projetavam-se na consolidação histórica do Direito estatal. Grossi (2006) também sugere que a compreensão da propriedade moderna gestada na Idade Média deve ocorrer acompanhando a construção do Estado na Europa, dando destaque à Revolução Francesa e ao reconhecimento da propriedade como um direito inerente à natureza humana, sendo consagrada na Declaração de Direitos do Homem e do Cidadão de 1789 no seu artigo 17. Em 1804 a propriedade, assim concebida como um direito natural, inalienável e imprescritível, foi confirmada pelo Código Civil Francês, também chamado de Código de Napoleão. Fachin (1988, p. 16) dispõe que a afirmação máxima do direito de propriedade, "nos moldes próximos ao de hoje contemplado entre nós se dá com o Code Napoleón, o Código da Propriedade, em seu artigo 544, pri- 
meira parte: La propriété est Le droit de jouir et disposer dês choses de la manière plus absolue". ${ }^{1}$ Para Grossi (2006, p. 11), trata-se de um singular arquétipo jurídico que, inicialmente, pode ser qualificado de napoleônico-pandectístico, isto é, "uma noção de propriedade não somente resolvida na apropriação individual, mas em uma apropriação de conteúdo particularmente potestativo".

Tanto o Código Francês quanto o Código Italiano de 1865 "estatuaram que a propriedade é o direito de gozar e dispor do bem de modo absoluto", de acordo com Fachin (1988, p. 16). Este arquétipo, para Grossi (2006, p. 11), foi compactado para que sobreviva no social, mas afunde no ético e apenas flutue no jurídico "graças à operação lucidíssima da consciência burguesa que, de Locke em diante, fundou todo o dominium rerum sobre o dominium sui e viu a propriedade das coisas como manifestação externa", idêntica àquela propriedade intra-subjetiva que todo eu teria de si mesmo e idêntica aos seus talentos, propriedade esta absoluta porque corresponderia à "natural vocação do eu a conservar e a enrobustecer o si: em outras palavras, um meu que, como veremos depois, torna-se inseparável do mim e que inevitavelmente se absolutiza".

Grossi denuncia essa visão "agradavelmente antropocêntrica". São, pois, destes alicerces especulativos que nasce a visão individualista e potestativa da propriedade que comumente se chama "propriedade moderna", de acordo com Grossi (2006, p.12), um produto histórico que "por ter se tornado bandeira e conquista de uma classe inteligentíssima, foi inteligentemente camuflado como uma verdadeira redescoberta". Para o pensador, quando os juristas, tardiamente, com as análises revolucionárias e pós-revolucionárias na França e com as pandectísticas na Alemanha, traduzem, com o auxílio do instrumental técnico romano, as instituições filosófico-políticas em regra de Direito e as organizam, o que era produto histórico se deforma. De respeitável consolidação histórica torna-se conceito e valor: "não o produto de uma realidade mutável tal como foi se cristalizando, mas o cânone com o qual medir a mutabilidade da realidade" (GROSSI, 2006, p. 12).

A propriedade moderna, por fim, retomaria, para superar a propriedade medieval, uma específica herança da propriedade romana: uma mentalidade angulosamente proprietária, baseada numa relação de validade a partir de uma codificação, afastando um vigoroso princípio de efetividade que havia emergido no medievo. O Estado moderno lhe dá a indispensável plataforma de validade de que carecia desde a queda do Império Romano. A propriedade decorre de uma abstração: o meu eu, com exclusividade. São por isso culturas jurídicas rigorosamente individualistas, a romano-clássica e a burguesa-moderna, porque "aqui a propriedade construída sobre o sujeito é tão caracterizada pelas suas fundações ético-políticas a ponto de não ter nada a compartilhar não digo com as situações de simples detenção, mas sim com todas as outras situações reais" (GROSSI, 2006, p. 56). O traço tipificador da propriedade moderna é uma abstração, decorrente da interpretação burguesa do mundo social.

Por isso, historicizar o arquétipo é o que se exige do historiador do Direito. O século 20, portanto, foi capaz de produzir novos discursos históricos que desafiam as narrativas oficiais. Esse desafio, como já foi mencionado, é marcado por avanços e retrocessos e na gramática jurídico-constitucional vinculou-se à ideia de função social da propriedade a tarefa de simbolizar essa nova mentalidade. A função social da propriedade corresponde ao aspecto jurídico, formal, de desafio a uma mentalidade inscrita nas instâncias sociais e econômicas da vida humana. A Constituição de Weimar de 1919 inaugura a busca por esse reconhecimento de uma nova ordem econômica e social sobre a propriedade, de acordo com Fachin (1988), adotando em seu texto a função social da propriedade. A partir de tal Constituição, a ideia da função social da propriedade alcança a categoria de princípio jurídico, numa tentativa de alteração conceitual do regime tradicional para incorporar ao mundo jurídico o pensamento de solidariedade social em relação à posse e à utilização da propriedade.

Os limites dessa tentativa podem ser apontados com exatidão na história da propriedade no Brasil. A partir do contexto da formação do Estado-Nação brasileiro, no decorrer do século 19, até os trabalhos da Constituinte de 1987, a predominância de uma específica mentalidade sobre a propriedade se projeta com indiscutível precisão. O trabalho de pesquisa segue sob a advertência de Grossi (2006, p. 16) de que, conquanto a propriedade seja o centro de uma sociedade e de uma civilidade, ela nunca será somente um problema

\footnotetext{
Registre-se aqui a advertência de Grossi (2006, p.78) de que o jurista não deve "ficar ofuscado por aquele maldito artigo 544, que, com seu triunfalismo, tanto contentou a retórica burguesa do século XIX, ao ponto de consentir aos futuros juristas identificar nele a face da nova propriedade jurídica". O historiador sugere que "pacatamente e sem nenhum pré-conceito, olhasse um pouco mais profundamente a sistemática do Código no que diz respeito aos direitos reais e a própria estrutura do artigo 544. O palimpsesto emergirá com suficiente nitidez".
} 
técnico, a ser resolvido em termos de normatividade: "a propriedade não consistirá jamais em uma regrinha técnica, mas em uma resposta ao eterno problema da relação entre homens e coisas, da fricção entre mundo dos sujeitos e mundo dos fenômenos", advertindo àquele que se põe a reconstruir sua história que "longe de ceder às tentações isolacionistas, deverá, ao contrário, tentar colocar-se sempre no interior de uma mentalidade e de um sistema fundiário com função eminentemente interpretativa". Em busca desta interpretação, foram revisitadas algumas compreensões do Brasil e finalmente os debates constituintes.

\section{O DIREITO DE PROPRIEDADE NO BRASIL E O CONTEXTO DA CONSTITUINTE DE 87}

Grossi (2006, p. 61) ensina que "como esquema antropológico tarda a morrer e, para além da persistência e da mudança nos regimes positivos, pode mudar somente quando as certezas antropológicas que o provocaram e sustentaram se dispuserem a mudar", para elucidar questões ligadas à reforma agrária no Brasil será preciso uma imersão na trajetória histórica desse debate. A História brasileira começa a ser traçar, na visão eurocentrista, no século 15 , quando, no contexto mercantilista, diversos países europeus começaram suas buscas por novas riquezas e terras distantes do Velho Continente, superando o feudalismo. A formação do Estado brasileiro foi objeto de diversos olhares no século 20. Alencastro (2000), por exemplo, preconiza o entendimento da formação do Brasil pela compreensão do comércio internacional no Atlântico Sul, especialmente de escravos, destacando o papel da África e da Ásia durante os séculos 16 e 17 no mundo capitalista mercantil no qual importavam a posse das grandes rotas marítimas e dos pontos estratégicos de comércio (feitorias mais que colônias). Faoro (2001) defendeu a formação de um Estado patrimonial na Europa, depois da ruína do feudalismo, que se transplantou na América portuguesa com o ingresso do Brasil na rota do capitalismo mercantilista.

É nesse contexto que a questão da terra começa a ser desenhada no Brasil, quando a Europa impõe à América seu estilo comercial e sua exploração, sendo transferido para o Brasil o sistema adotado, quase um século antes, nas ilhas do Atlântico nas quais predominava a monocultura de cana-de-açúcar nas extensas faixas de terra chamadas capitanias hereditárias (FAUSTO, 2013). O modelo de feitorias, adotado em praticamente toda a costa africana pelos portugueses, não foi utilizado na costa do Brasil. O sistema de capitanias levou a que se formulassem teses da natureza feudal da colonização, pois tais pedaços de terra eram disponibilizados pela Coroa para nobres de Portugal que tinham por dever, com seus próprios recursos, explorar, defender e povoar a terra, com as questões políticas, administrativas e jurídicas sendo de responsabilidade dos donatários.

Tal tese fora superada e têm-se, então, as capitanias como uma tentativa transitória de colonização da nova terra que teria baixo custo para a Coroa Portuguesa e, consequentemente, integraria a colônia à economia europeia. Posteriormente, entretanto, as capitanias foram sendo retomadas pela Coroa, passando a pertencer ao Estado português: "entre 1752 e 1754, o Marques de Pombal completou praticamente o processo de passagem das capitanias do domínio privado para o público" (FAUSTO, 2013). A monarquia lusitana utilizou também um modelo legislado tradicional: as sesmarias, que vigoraram de 1530 até 1822, como uma concessão administrativa do domínio, não uma transferência de propriedade.

Para Faoro (2001), importava também compreender a construção de uma mentalidade, pois o senhor de latifúndios e escravocrata incorpora o status de nobreza e aristocracia, de natureza rural. Assim, o fazendeiro, "sempre vinculado ao açúcar, se transmuta em nobre, por analogia com o aristocrata europeu, também ele proprietário de terra". A imensidão territorial do Brasil pulverizou a autoridade portuguesa, fixando nas localidades a autoridade política e anulando o poder da Coroa pela distância, pela dificuldade de acesso e pela falta de estrutura, o que fez com que a autoridade lusa chegasse enfraquecida ao Brasil e fortalecesse o poder local, em que o público e o privado, muitas vezes, confundiam-se. Dessa forma, "de nobre se faz culto e instruído, exigindo o poder político, que a independência lhe traria, em plano nacional, acima do refúgio de quatro séculos nas acanhadas municipalidades" (FAORO, 2001, p. 153).

Faoro dispõe do prestígio na formação da mentalidade sobre o Brasil que the concede o reconhecimento de ter dotado a inteligência brasileira de certas ideias-forças, de acordo com Souza (2015), ou seja, ideias que se tornam vida prática da sociedade brasileira contemporânea. Embora com vigorosas críticas à tese de Faoro, Souza $(2015$, p. 55) destaca sua contribuição na perspicácia de perceber o prematuro processo de centralização e monetarização das bases sociais do poder real em Portugal que possibilitará que o pequeno reino 
disponha de reservas suficientes para a aventura ultramarina, "fase heroica do povo português que marcará a história desse pequeno país por seis séculos", destacando o uso do Direito Romano como modelo de pensamento, ideal de justiça e instrumento de organização administrativa e jurídica do domínio do príncipe. Para Souza (2015), a tese do patrimonialismo serve à identificação de um estamento estatal necessariamente prejudicial à sociedade brasileira, sendo a principal ideia-força do liberalismo conservador brasileiro, contribuindo, sobretudo, para empobrecer um debate sobre o espaço público e a política no Brasil.

O patrimonialismo defendido por Faoro, de toda sorte, com a indefinição entre o público e o privado, fortaleceu as elites agrárias locais. Ademais, favoreceu a construção de um Estado-Nação preocupado com a defesa dos interesses dos donos das propriedades, que eram os donos dos meios de produção e geradores de riqueza na economia agrícola instalada desde os primórdios da História brasileira. Primeiro com a exportação do açúcar e depois do café, a exploração da terra, no caso brasileiro, foi e ainda é umas das destacadas fontes de riqueza para o país e um dos principais motivos de concentração da terra.

Algumas peculiaridades devem ser citadas. Ao longo desse processo de formação da mentalidade moderna no Brasil, a visão indígena do bom selvagem é trocada, ainda no século 16, pela ideia do selvagem que deve ser civilizado ou domesticado pelo descobridor, a quem é legítimo explorar e ter sobre ele propriedade, como se fosse uma coisa. Por outro lado, cristalizou-se a noção, advinda do sistema jurídico português, de que um cargo ou função pública eram patrimônio pessoal do seu ocupante. Dessa forma o poder público era exercido como exclusividade por um extrato social constituído por oligarquias agrárias e por grandes proprietários de terra. Outra peculiaridade da questão da propriedade no caso brasileiro é a atuação da Igreja Católica, pois "não raro, durante quase um século, a questão agrária se expressou por meio de tensões religiosas, de confronto sangrento entre o catolicismo popular e o catolicismo institucional ancorado no aparelho do Estado", mesmo depois da separação entre a Igreja e o Estado na República. De acordo com Martins (1999, p. 99), havia uma confusão entre a questão agrária, a religião e a política, que se confundirá também em uma questão policial e militar, como aconteceu em Canudos, no Contestado e em vários outros episódios das lutas sociais no campo, incluindo casos relativamente recentes, do tempo da ditadura: "um balanço apropriado do conflito fundiário nas últimas décadas nos revelaria que ele é apenas um subtema de conflito maior e mal definido entre o Estado oficialmente laico e a Igreja".

O sistema de sesmarias foi extinto por meio de uma Resolução em junho de 1822. Assim, tem-se o fim da concessão administrativa ao domínio, que consistia em determinada gama de poderes e certa dose de exclusividade. Em lugar da concessão do poder público, a terra se adquire pela herança, doação, compra e principalmente pela ocupação. A posse torna-se transmissível por sucessões e alienável pela compra e venda. Em 1850, a Lei de Terras consagra o sistema da compra de terras devolutas. Nesse período compreendido entre o ano de 1822, com o fim do regime sesmarial, e o ano de 1850, com a promulgação da Lei de Terras, há um vácuo legislativo de quase 30 anos que ficou conhecido como "Império das Posses" ou "fase áurea dos posseiros", pois não existia nenhum tipo de normatização da terra, com a posse constituindo a única forma de aquisição. Nesse período, de acordo com Alcântara Filho e Fontes (2009), aumenta paulatinamente o número de posseiros, de grandes propriedades e também marca a formação das oligarquias rurais no Brasil.

Após a Lei de Terras de 1850, a questão da propriedade fundiária e da desconcentração da terra foi ocultada. Apenas em 1964 foi objeto de preocupação na reforma de base proposta por João Goulart. O Estatuto da Terra, de 30 de novembro de 1964, substitui a lei de 1850, delimitando o módulo rural e estabelecendo o conceito de função social da propriedade. Tal Estatuto pode ser considerado a primeira de várias reformas necessárias ao modelo da propriedade fundiária e na forma de distribuição e consequente desconcentração da terra agrária no Brasil. O tema encontrou novamente espaço para uma ampla discussão na Constituinte de 1987, por meio da qual é possível visualizar o acerto da afirmação de que a questão agrária é "um conjunto de pontas desatadas desse longo e inacabado processo histórico" (MARTINS, 1999, p. 101). Uma análise dos trabalhos da subcomissão desvelou mais limitações e omissões que conquistas e avanços, bem como a manutenção do status quo agrário brasileiro. Para Martins (1999, p. 102), "é evidente que há no Brasil uma questão agrária. Mas, uma questão agrária que parece distanciada das condições históricas de sua solução definitiva, porque essa sociedade perdeu as oportunidades históricas que teve para resolvê-la." E isso ocorre porque a questão agrária brasileira "tende a aparecer residualmente como um problema social não referido a uma questão estrutural" (MARTINS, 1999, p. 102). 
A ideia de limitar o direito de propriedade pairava sobre a Constituinte de 1987. Segundo Abramo (1985), o Brasil, pelo prolongado domínio exclusivo de uma classe sobre as outras, tornou-se um país sui generis, que exigia uma Constituição sui generis, que necessariamente limitasse o direito de propriedade da terra e da propriedade urbana. Para ele, a Constituição brasileira a ser preparada deveria ter levado em conta fato irrecorrível da realidade brasileira, a saber, que quatro quintos da população brasileira sofrem, à semelhança dos escravos, constrições e constrangimentos iguais, e que "noventa por cento do povo brasileiro não têm acesso a quase nenhuma informação realmente importante e que de verdade não participam de nenhum processo realmente decisório" (ABRAMO, 1985, p. 46).

Para superar essas condições seria preciso uma Constituição historicamente adequada, derivada de uma mobilização que refletisse a correlação de forças para reorganizar a sociedade brasileira, conforme afirmado por Marini (1985) ao analisar as possiblidades e os limites de uma Assembleia Constituinte naquele contexto histórico. Nesse cenário, Gomes (1985, p. 84) advertia que "uma nova Constituição é o acontecimento de maior violência na história de uma Nação". Não se poderia negar a centralidade da questão agrária em um país no qual o grande capital se tornou a propriedade de terra, após a abolição da escravidão.

Martins (1999, p. 102) ressalta o fato de que a promulgação da Lei Áurea tenha ocorrido durante o governo de um gabinete conservador, constituído por bacharéis e grandes proprietários de terra. Para ele, o modo como se deu o fim da escravidão foi o responsável pela institucionalização de um direito fundiário que impossibilita desde então uma reformulação radical da estrutura agrária brasileira. Destaca também que a reivindicação da reforma agrária nasceu nos anos 50 do século 20 como exigência dos setores esclarecidos da classe média urbana, de setores católicos conservadores e familistas, marcados por moderado e cauteloso empenho, de alguns setores católicos de esquerda e de uma fração das esquerdas laicas, sendo, "portanto, mais por um impulso ideológico e por motivação humanitária voltada para a solução das injustiças sociais do que, propriamente, por ser expressão de uma inadiável necessidade de mudança". Ocorre que, em muitas regiões do Brasil, grandes proprietários de terra haviam se tornando empresários capitalistas, tanto na região canavieira do Nordeste quanto na região cafeeira do Sudeste, situação agravada pelos incentivos fiscais concedidos durante a ditadura militar. Assim, "aquele que pode tomar consciência das contradições que perturbam a reprodução ampliada do capital foi compensado das irracionalidades da propriedade da terra como titular de renda fundiária" (MARTINS, 1999, p. 100).

Mesmo diante deste cenário, a Constituinte de 86/87 se estabelece com a compreensão, por parte de alguns setores, de que não se tratava apenas de efetuar uma reforma agrária, mas de revisar o conceito do direito de propriedade, contestado em sua legitimidade. Um limite ao direito de propriedade, na ideia de função social da propriedade, se inscreve na história constituinte brasileira do século 20. A Constituição de 1824 e a de 1891 silenciaram acerca de qualquer limite ao direito de propriedade em geral, tal como preconizava o individualismo liberal burguês proclamado pelas elites de então. Foi somente na Constituição de 1934 que, de forma expressa, se faz referência à atividade do proprietário, ao garantir, no artigo 113, o direito de propriedade, mas desde que não exercido contra interesse social ou coletivo. A Constituição de 1946 inova ao dispor, em seu artigo 141, a garantia do direito de propriedade, salvo nos casos de desapropriação por necessidade ou utilidade pública, ou por interesse social, mediante prévia e justa indenização em dinheiro, introduzindo, assim, a desapropriação por interesse social, o que se assemelha ao conceito de propriedade ligada a sua função social.

Nos anos 50 vários eram os desafios em um cenário conturbado do ponto de vista ideológico. Grupos antagônicos preconizavam a reforma agrária, conforme Martins (1999, p. 102), uns em nome do conservadorismo, outros em nome da revolução. As esquerdas estavam, a respeito, divididas: de um lado, havia uma proposta de reforma agrária "claramente conservadora, sobretudo a mal definida reforma católica". De outro lado, havia uma proposta de "reforma agrária radical, a das Ligas Camponesas, também ela não muito clara. A Igreja estava preocupada com a questão social do campo, mais do que com a questão agrária, em posição oposta à do Partido Comunista e por oposição a ele". Martins cita ainda documento pioneiro de Dom Inocêncio, bispo de Campanha, em Minas Gerais, de 1950, no qual a Igreja reconhecia o risco político das migrações, do êxodo rural e do desenraizamento, que "supostamente lançariam os pobres do campo nos braços dos comunistas nas cidades de destino, como Rio e São Paulo". A Igreja estava preocupada em pensar alternativas para "preservação da unidade familiar de produção, do trabalho familiar e da família, trabalho familiar que incluía o trabalho não autônomo dos colonos das fazendas de café no Sudeste e dos moradores das fazendas 
de cana-de-açúcar no Nordeste", uma vez que a continuidade era comprometida pelas migrações para o meio urbano. Por fim, afirma Martins que a reforma agrária, ainda sem qualquer definição, passava a ser, para a Igreja, um objetivo "contido e limitado pelo temor de questionar o direito de propriedade e os direitos da classe de proprietários de terra".

O movimento em prol de maior justiça social no campo tomou grandes proporções em 1960. Tal fato acarretou, no governo dos militares, na criação da Lei 4.504/64, também conhecida como Estatuto da Terra, resultante do clima de insatisfação no meio rural brasileiro e do temor de uma revolução dos agricultores. Diversos foram os movimentos nacionalistas, desde meados dos anos 50 , que trouxeram problemas não anteriormente questionados e promoveram outras perspectivas de compreensão do Brasil. Marini (1985, p. 18) lembra que "o campesinato iniciou um processo de organização e luta sem precedentes na história do país". Outros movimentos tomaram forma, como as grandes massas urbanas mobilizando-se em prol da nacionalização do petróleo, a consciência da mulher sobre seus direitos, o direito de greve de 1953, as lutas reformistas e anti-imperialistas dos anos 60, entre muitos outros, que foram obstruídos e desarticulados com a ditadura militar. Para Marini (1985, p. 19), se o desenvolvimento social e institucional do país viu-se freado ou desviado, "a responsabilidade cabe ao regime contrarrevolucionário de 1964, que impôs ao Brasil durante décadas uma autêntica camisa de força". Um dos maiores desafios da Assembleia Nacional Constituinte de 86/87 era, portanto, resgatar historicamente esses movimentos do seu desvio histórico; entre as questões, a reforma agrária.

\section{O RESGATE HISTÓRICO DAS DISCUSSÕES SOBRE A PROPRIEDADE E A REFORMA AGRÁRIA NA CONSTITUINTE DE 86/87}

De acordo com Silva (1988), o conservadorismo, antigo e desconectado da realidade, encontra-se nos debates constituintes na própria conceituação da propriedade. A disputa pela propriedade de terras no Brasil conjuga o empresário de terras e a ênfase na rentabilidade desse bem. Para Silva (1988, p. 9), "dos maiores banqueiros e industrialistas aos médios comerciantes de uma pacata cidade do interior, toda a burguesia envolveu-se na propriedade rural, na empresa agrícola." A possibilidade de reverter em outro modelo o uso e a propriedade de terras, por meio de uma reforma agrária e urbana estabelecida por uma Constituinte, significava modificar a estrutura da sociedade brasileira. Diante das mudanças que poderiam acontecer, a Assembleia Nacional Constituinte (ANC) foi palco de inúmeras desorganizações, autoritarismo e situações vexatórias, precisando se proibir expressamente o trânsito de pessoas armadas no Plenário.

De acordo com Silva (1988), em termos de providências objetivas para a redação de uma nova Constituição para o Brasil, pode-se tomar a data de 7 de agosto de 1984 como o início do processo constituinte. Nessa ocasião foi firmado entre os dois maiores partidos da época, o Partido do Movimento Democrático Brasileiro (PMDB) e o Partido da Frente Liberal (PFL), o pacto político conhecido como Aliança Democrática (AD), destinado, fundamentalmente, a garantir a eleição de Tancredo Neves para a Presidência da República. Entre os compromissos estavam também a convocação da Constituinte em 1986 e a reforma agrária, com a melhoria de vida do homem do campo, conforme previsto no Estatuto da Terra.

As limitações que ocorreram no processo constituinte iniciam-se na sua convocação, quando, em 28 de junho de 1985, José Sarney encaminhou ao Congresso Nacional proposta de instalação de uma ANC, criando, assim uma constituinte congressual e não uma verdadeira Assembleia Nacional Constituinte, o que gerou uma série de conflitos de atribuições nos trabalhos constituintes. Desse modo, muitos foram os "lances, manobras e artimanhas que privaram o Brasil de convocar uma Assembleia Nacional Constituinte de verdade, que sinalizasse o fim do longo período de intervenção militar iniciado em 1964" (SILVA, 1988, p. 29). A cerimônia de sua instalação sinalizou desde logo o ambiente conservador que vivia o país e a tendência que inegavelmente dominaria na nova Constituição. De acordo com Silva (1988, p. 30), o ministro José Carlos Moreira Alves, presidente do STF, que presidiu a cerimônia de instalação, "pronunciou na ocasião uma peça oratória seiscentista, e o presidente eleito da ANC não teve forças para permitir que os próprios representantes do povo - os constituintes - usassem da palavra durante a cerimônia". Foram os primeiros tumultos que prenunciavam outros incidentes mais graves, sobretudo nos debates relativos à questão agrária. 


\section{Debate}

Os movimentos sociais, contudo, estavam mobilizados. Entre esses grupos, sobretudo no caso da questão agrária, tem-se a posição dos trabalhadores na agricultura e da Igreja Católica. A Confederação Nacional dos Trabalhadores na Agricultura (Contag), entidade representativa dos trabalhadores rurais brasileiros, elaborou um documento contendo dez propostas relativas à questão agrária, que se relacionava principalmente com a reforma agrária e a definição da atuação do Movimento dos Trabalhadores Rurais Sem Terra (MTRST) na eleição dos futuros constituintes. Foi elaborado o documento "Os Trabalhadores Rurais e a Constituinte", no qual se propõe que "a Reforma Agrária tem que receber tratamento adequado. A Constituição tem que fazer uma diferenciação entre desapropriação por interesse social para fins de Reforma Agrária e a desapropriação por necessidade ou utilidade pública" (SILVA, 1988, p. 33).

Contrapondo-se à Contag e ao MTRST, posicionaram-se as entidades representativas dos donos de terra, como o caso da União Democrática Ruralista - UDR - associação civil criada em maio de 1985 por grandes proprietários de terras com a finalidade de defender a propriedade privada e como expressão da radicalização patronal rural contra a política agrária promovida pelo governo federal no começo da administração do presidente José Sarney (1985-1990), e da tradicional Sociedade Rural Brasileira, que, de acordo do Silva (1988, p. 35),"no passado defendia principalmente os grandes fazendeiros de café e que hoje está mais sob a influência de grandes pecuaristas".

A Igreja Católica continuou sua atuação na questão agrária brasileira comprometendo-se com a realização de uma reforma agrária eficiente no Brasil, a partir de sua opção pelos pobres. De acordo com Silva (1988), a Igreja Católica, em seu posicionamento diante da Constituinte, reafirmou seu apoio a uma mudança em profundidade da nossa estrutura agrária por ocasião da 24a Assembleia Nacional da Confederação Nacional dos Bispos do Brasil (CNBB), tendo o jornal Folha de S. Paulo publicado, na edição de 4 de abril de 1986, matéria na qual a CNBB pede mobilização popular pela Constituinte. Nessa Assembleia católica foi apresentado aos bispos brasileiros um documento que enfatizava os principais pontos sobre a questão da terra, a propriedade e a sua função social. O documento intitulado "Exigências Cristãs de uma Nova Ordem Constitucional" dispunha, no Inciso 96, a ideia de que o direito de propriedade não é absoluto e deve estar ligado ao uso comum; no Inciso 97 afirmava a injustiça de classes poderosas conservarem terras improdutivas diante da existência de famílias carentes e no Inciso 103 defendia a desapropriação de bens, terras e propriedades improdutivas por razões de interesse social.

Continuando a montagem da ANC, por iniciativa do Executivo, foi instalada a Comissão Provisória de Estudos Constitucionais (CPEC) pelo presidente José Sarney, também conhecida como Comissão Afonso Arinos ou Comissão dos Notáveis. Contou com a presença de participantes considerados de esquerda, como José Francisco da Silva, Jorge Amado, Cristóvam Buarque, Celso Furtado e José Afonso da Silva. O resultado dos trabalhos da CPEC sequer foi aproveitado posteriormente. De acordo com Silva (1988, p. 43), o destino que Sarney deu ao Anteprojeto Afonso Arinos, o esquecimento, caracterizou a Constituinte de 1987/1988 como "uma daquelas que iniciaram seus trabalhos sem qualquer roteiro prévio, diferenciando-se assim das Cartas de 1891, 1934, e 1946, que contaram com anteprojetos preparados por comissões adredemente nomeadas." Tal fato acirrou as discussões sobre a elaboração de um Regimento Interno e outros regulamentos que deveriam orientar e organizar os trabalhos da ANC. Assim, na falta de um roteiro prévio, o Regimento Interno ganhou uma grande importância tático-política, acarretando uma Constituição pouco sistematizada. Os desdobramentos em torno da discussão inicial sobre a ausência de um Regimento Interno, desencadeando o surgimento do chamado "Centrão", foram decisivos para os descaminhos da reforma agrária.

As discussões havidas nas subcomissões e comissões, bem como no Plenário da Constituinte, são um campo de estudo privilegiado para a percepção das disputas e dos conflitos na sociedade brasileira, pelo acirramento ideológico, com o crescimento da UDR e a escalada da violência no campo, pela importância que a propriedade de terras teve e tem na formação das grandes fortunas no Brasil. Em março de 1987 foi aprovado o Regimento Interno da ANC, incluindo, na Comissão Econômica, uma Subcomissão para a Reforma Agrária, o que, em tese, sinalizou uma vitória progressista. Trouxe, ainda, seguindo a tradição parlamentar brasileira, o cargo de relator, o qual teria controle sobre os trabalhos das Comissões e Subcomissões.

As disputas acirradas sob a questão da terra no Brasil Constituinte prosseguiram até o final dos trabaIhos da ANC, atravessando, sempre com brigas e incidentes, as etapas da Comissão de Ordem Econômica, da Comissão de Sistematização e do Plenário, em conflitos paralelos acontecidos nas galerias, bastidores, na Praça dos Três Poderes e em diversos outros campos em que se travou a luta constitucional. Fora instaurada 
a Subcomissão de Política Agrícola, Fundiária e da Reforma Agrária, por onde passaram os representantes das entidades do chamado Movimento Popular, três delas vinculadas à Campanha Nacional pela Reforma Agrária - CNRA: a Associação Brasileira da Reforma Agrária - Abra, a Comissão Pastoral da Terra - CPT, e a já citada Contag. Plínio Guimarães, em nome da Abra, lembrou que "o novo Legislador terá por inimigos todos aqueles a quem as leis antigas beneficiavam" (SILVA, 1988, p. 58). Luiz Edson Fachin, em nome da CNRA, defendeu cinco pontos de sustentação da reforma agrária, entre os quais se destaca "a definição constitucional do direito de propriedade que ele localiza, hoje, no artigo 160 da CF conjugado com o § 20 do artigo 2 ㅇ do ET, que desde 1964 imprime à propriedade da terra uma função social". Tais propostas não interessavam a boa parte da Subcomissão, "simplesmente pelo fato de que, ao falarem de Latifúndio, Perda Sumária e Desapropriação por Interesse Social, estavam atingindo diretamente donos de terra sentados à sua frente", conforme descreve Silva (1988, p. 59).

Completando a participação das entidades populares que compõem o Movimento, ocorreu a exposição da Contag, feita pelo presidente José Francisco da Silva, que defendeu a unidade familiar de produção agrícola e que "não escondeu sua opinião sobre a UDR: são aqueles que articulam a compra de armas e contratam pistoleiros para expulsar os trabalhadores" (SILVA, 1988, p. 60). Por fim, o posicionamento da CPT, por Hamilton Pereira da Silva, foi no sentido de entregar ao relator um documento sobre a violência no campo, intitulado "Assassinato no Campo, Crime e Impunidade", considerando a violência no campo como "filha do monopólio da terra, filha do latifúndio, numa situação em que nem o Estado nem latifúndio reconhecem o direito à cidadania, não reconhecem sequer o direito à vida" (SILVA, 1988, p. 61). Hamilton Pereira da Silva utilizou ainda as palavras do padre Ricardo Rezende para denunciar o trabalho escravo em 29 fazendas e entregou para a Subcomissão uma relação na qual constavam nomes como Bradesco, Bamerindus e Banco Mercantil.

Como representantes de entidades patronais tem-se a Confederação Nacional da Agricultura (CNA), a Sociedade Rural Brasileira (SRB) e a Organização das Cooperativas Brasileiras (OCB), tendo essa última a presidência do engenheiro Roberto Rodrigues, que defendeu que "a instituição da propriedade privada é a contrapartida material do conceito de liberdade individual. Corresponde ao direito assegurado pela sociedade de o indivíduo obter, através da livre iniciativa, o controle absoluto de bens materiais" (SILVA, 1988, p. 63). Como representantes do governo, houve a participação da Embrater, Embrapa, Incra e o ministro Dante de Oliveira, do Ministério da Reforma Agrária e Desenvolvimento (Mirad). O presidente do Incra defendeu a "imissão automática na posse dos imóveis rurais desapropriados por interesse social e a efetivação do Fundo Nacional de RA previsto no ET" (SILVA, 1988, p. 63). Já o ministro Dante de Oliveira fez sua exposição sobre a questão agrária brasileira com fundamento no pensamento de Tancredo Neves, repudiando a especulação de terras: "na medida em que a terra é vista como um bem de especulação e um instrumento de domínio (...) perverte-se toda a base justa da propriedade fundiária" (SILVA, 1988, p. 63).

As principais questões ligadas ao campo foram colocadas, em destaque, no Pleno da Constituinte. Mesmo diante de um esforço tão intenso e tão rico de contribuições, vivido durante vários dias de tensão, foram pífios os resultados dos trabalhos da Subcomissão. A 15a reunião da Subcomissão foi convocada para leitura do parecer do relator Oswaldo Lima Filho, que apresentou, mediante manifestações, a favor e contra, avanços e recuos. Após algumas modificações, como a substituição de "obrigação social" pela de "função social", o segundo Anteprojeto estava pronto para entrar em discussão, sob grande tensão. Para avaliar o clima reinante, Silva (1988) afirma que, ao abrir a reunião, o seu presidente, senador Edison Lobão (PFL/MA), advertiu as galerias, invocando o artigo 40 do Regimento Interno, que era permitido a qualquer pessoa assistir às sessões das galerias, desde que esteja desarmada e guarde silêncio. Não obstante, foram apreendidas 50 armas na ocasião.

Por diversas vezes conservadores tentaram eliminar a palavra simultaneamente, que deveria amarrar os parâmetros da função social da propriedade. Chegou-se mesmo a ocorrer o estranho caso do sumiço do deputado Benedicto Monteiro, exatamente na hora da votação decisiva da questão agrária. Antes de passar para a fase do Plenário, o deputado Plínio de Arruda Sampaio (PT/SP) propôs a Ulysses Guimarães, presidente da ANC, a realização de sessões extraordinárias em que temas-chave pudessem ser novamente discutidos, desta vez mais livremente. Conforme o Regimento Interno, artigo 13, entretanto, fora formada a Comissão de Sistematização, composta por 49 membros e presidida por Afonso Arinos. As Comissões ainda não haviam concluído seus trabalhos quando a Comissão de Sistematização realizava sua primeira reunião. Foi divulgado o Anteprojeto de Constituição que trouxe em seu texto a criação da Justiça Agrária e o Imposto Territorial Rural. 
Em etapa seguinte surgiram dois Projeto de Constituição, os conhecidos Cabral 1 e seu substitutivo, Cabral 2. Um dos maiores avanços do Cabral 2 em relação ao primeiro é que no novo texto "não aparece mais a cabalística palavra prévia que precisou de um Al para ser eliminada da CF brasileira. Assim, a desapropriação por interesse social, desde logo, não precisa ser paga com antecipação" (SILVA, 1988, p. 132). Já a Justiça Agrária, que existia em Cabral 1 e seria semelhante à Justiça especial, como a trabalhista e a militar, desapareceram em Cabral 2, passando as questões de direito agrário, no artigo 128, para competência dos juízes federais. Cabral 2 preferiu não definir a função social. No dia 10 de novembro, Cabral 2 foi levado para votação, resultando no Projeto da Comissão de Sistematização que seria levado ao Plenário. De acordo com Silva (1988, p. 137), sob uma intensa movimentação nos bastidores, com "a presença ostensiva de lobby da UDR, a compartimentação dos diversos grupos e a própria tensão vivida nas etapas anteriores, tudo isso mantinha o clima de suspense quando a sessão foi aberta por Fernando Henrique Cardoso (PMDB/SP)".

Nesse clima, alguns blocos se alinharam formando os chamados progressistas (PT, PDT, PC do B), e o grupo de direita liderado pelo senador José Richa (PMDB/PR). Nesse contexto, surge o "Centrão", após 331 assinaturas e sob muita expectativa, exatamente no dia da discussão do Capítulo relativo à questão agrária. Assim, o bloco da direita defendia que o uso e não o direito deve ser condicionado ao cumprimento da função social. No sentido oposto, o bloco Progressista tenta manter a redação do Cabral 2 nos artigos 209, garantindo a função social, e 212, que disciplinava a imissão de posse das terras desapropriadas por interesse social para fim de reforma agrária.

Mais uma vez iniciam-se as discussões e votação sobre o tema questão agrária e reforma agrária, apresentando, em relação à CF de 1964, alguns outros recuos e alguns outros avanços. Um grande avanço foi a eliminação do vocábulo "latifúndios" do texto constitucional, assim como a introdução da palavra "até" que leva a uma liquidação imediata de títulos que antes tinham prazo certo de 20 anos. Já a Direita Radical, na figura de Roberto Cardoso Alves (PMDB/SP) afirmou: "Quem irá cumprir a função social? Somente quem tem dinheiro no bolso (...) esses bagunceiros de esquerda não querem reforma nem política agrícola. Querem é debilitar o direito de propriedade" (SILVA, 1988, p. 153). O surgimento do Centrão é o prenúncio de novas batalhas. Um dos seus objetivos do era afastar o Regimento Interno da ANC, visando a anular o projeto da Comissão de Sistematização e futuras alterações no texto constitucional produzidas por essa Comissão. Assim, em 25 de novembro de 1987 conseguiu essa vitória regimental que autorizava alterações de incisos, parágrafos, artigos e até títulos inteiros. Tal manobra levou a reforma agrária para o "buraco negro" de que fala Silva (1988, p. 157), uma vez que "no caso de não ser acolhida a emenda votada em regime de preferência, seriam necessários outros 280 votos para confirmar o texto saído da Comissão de Sistematização. Caso não fosse aprovada a matéria, não faria parte da CF". Assim, a manobra política que resultou na formação do Centrão e, sobretudo, na alteração do Regimento Interno da ANC, deu-se por interesse dos conservadores.

Silva (1988, p. 199) conclui que qualquer avaliação da Carta de 1988 precisa levar em conta o patamar em que ela colocou o segmento mais frágil da sociedade brasileira, uma vez que "conceder privilégios a extratos da população que já desfrutavam de uma razoável posição em termos de status e de renda não significa, necessariamente, melhorar o conjunto". A nova Constituição Federal "não diminuiu o terrível fosso que separa o sem-terra de seu algoz da UDR. Pelo contrário, a Carta de 1988 aprofundou o buraco da desigualdade, impedindo, definitivamente, que a questão agrária brasileira pudesse ser resolvida por via pacífica". Ressaltem-se os avanços simbólicos. A CF de 1988 trouxe a união indissociável entre a propriedade e sua função social ao positivar o direito de propriedade entre os direitos e garantias fundamentais previstos no artigo 5o para em seguida agregar a função social em inciso seguido, construindo um elo entre o direito de propriedade e a dignidade humana. A função social também segue, sucessivamente, a propriedade privada no artigo 170, incisos II e III do texto constitucional quando trata da ordem econômica.

No campo jurídico, essa perspectiva do direito de propriedade, antes delineado sobre o prisma privatista, incorporou o dever jurídico de agir em prol do interesse coletivo, por meio do exercício da função social. Houve, portanto, uma constitucionalização do direito de propriedade, retirando a questão apenas do âmbito privado e passando a fazer parte do direito público. Essa compreensão deveria orientar a constituição de ações prestacionais positivas a cargo do proprietário, estabelecendo para este obrigações de agir. No Brasil pós ANC, restou definido que proprietário de terra tem o uso, o gozo e a obrigação de atender à função social da propriedade. Essa definição deveria orientar toda uma política de terras no Brasil nos anos seguintes. 


\section{CONCLUSÃO}

Neste trabalho procurou-se afirmar que uma reforma na estrutura fundiária no Brasil requer a construção de uma nova mentalidade sobre a propriedade. No nosso país, a noção moderna de propriedade como uma projeção do eu individual, soberano, tornou-se obstáculo para que se formulem novas possibilidades para o tratamento jurídico da propriedade fundiária. Os debates constituintes de 1987 demonstraram a profundidade desta mentalidade e a disposição de defendê-la. O referencial teórico que autorizou esta conclusão foi o proposto por Grossi em estudo histórico sobre a formação da mentalidade para conceituar a propriedade moderna como uma superação da mentalidade medieval europeia.

A propriedade, conforme se apresentou nesta pesquisa, é sempre um dos princípios ordenadores de uma sociedade. Por isso é possível afirmar múltiplas compreensões sobre ela. Ter valor e função essencialmente alimentares, ligados à sobrevivência cotidiana, é completamente diferente da instalação de uma sociedade proprietária que considera a propriedade a projeção do indivíduo, de forma absoluta, para usar, gozar e dispor. Na modernidade, a relação entre homens e bens põe em jogo grandes interesses, tornando-se um risco para o estudo histórico, que tende a se tornar ideológico. Considerando a propriedade como uma formulação situada no centro do projeto moderno, foi constatado que teólogos e filósofos contribuíram para a construção de uma mentalidade moderna de propriedade, como projeção da sombra soberana do indivíduo moderno. A modernidade é a sociedade proprietária de Grossi.

A inserção de uma função social da propriedade no texto constitucional de 1988 somente terá algum impacto se for acompanhada de um amplo movimento civilista, no campo jurídico, e uma mudança de mentalidade, no campo social e econômico. Qualquer variação deste porte é historicamente lenta, trabalhosa e não acontece sem resistência e perdas. Ela precisa aninhar-se nas consciências e a sociedade brasileira parecer ser um modelo bem-sucedido de triunfo da propriedade moderna sem resquícios de outras formas medievais. A mentalidade proprietária parece manter-se firme no discurso jurídico oficial, desposado na doutrina civilista predominante e nas decisões judiciais.

\section{REFERÊNCIAS}

ABRAMO, Cláudio. Uma constituição diferente. In: SADER, Emir (Org.). Constituinte e democracia no Brasil hoje. São Paulo: Brasiliense, 1985.

ALCÂNTARA FILHO, José Luiz; FONTES, Rosa Maria Oliveira. A formação da propriedade e a concentração de terras no Brasil. Revista de História Econômica \& Economia Regional Aplicada, v. 4, n. 7, jul./dez. 2009.

ALENCASTRO, Luiz Felipe de. O trato dos viventes: formação do Brasil no Atlântico Sul. São Paulo: Companhia das Letras, 2000. COULANGES, Fustel de. A cidade antiga. São Paulo: Martin Claret, 2002.

FACHIN, Luiz Edson. A função social da posse e da propriedade contemporânea: uma perspectiva da usucapião imobiliária rural. Porto Alegre: Sérgio Antonio Fabris Editor, 1988. Disponível em: <http://docslide.com.br/documents/fachin-luiz-edson-a-funcao-social-da-posse-e-a-propriedade-contemporanea.html>. Vários acessos.

FAORO, Raymundo. Os donos do poder: formação do patronato político brasileiro. 3. ed. 7. reimpres. São Paulo: Globo, 2001. FAUSTO, Boris. História do Brasil. São Paulo: Edusp, 2013.

GOMES, Severo. Situação constituinte. In: SADER, Emir (Org.). Constituinte e democracia no Brasil hoje. São Paulo: Brasiliense, 1985. GROSSI, Paolo. História da propriedade e outros ensaios. Trad. Luiz Ernani Fritoli e Ricardo Marcelo Fonseca. Rio de Janeiro: Renovar, 2006.

KELLY, John. Uma breve história da teoria do direito ocidental. Trad. Marylene Pinto Michael. São Paulo: WMF Martins Fontes, 2010. LE GOFF, Jacques. Para uma outra Idade Média: tempo, trabalho e cultura no Ocidente; 18 ensaios. Trad. Thiago de Abreu, Lima Florêncio e Noéli Correia de Melo Sobrinho. 3. ed. Petrópolis, RJ: Vozes, 2014.

LOCKE, John. Dois tratados sobre o governo. 2. ed. São Paulo: Martins Fontes, 2005.

MACIEL, José Fábio Rodrigues; AGUIAR, Renan. História do Direito. São Paulo: Saraiva, 2007.

MARINI, Ruy Mauro. Possibilidades e limites da Assembléia Nacional Constituinte. In: SADER, Emir (Org.). Constituinte e Democracia no Brasil hoje. São Paulo: Brasiliense, 1985.

MARTINS, José de Souza. Reforma Agrária. O impossível diálogo sobre a história possível. Tempo Social., Rev. Sociol. USP, São Paulo, 11(2): p. 97-128, out. 1999 (editado em fev. 2000).

ROUSSEAU, Jean-Jacques. Discurso sobre a origem e os fundamentos das desigualdades entre os homens. Trad. Alex Marins. São Paulo: Martin Claret, 2006.

SADER, Emir (Org.). Constituinte e democracia no Brasil hoje. São Paulo: Brasiliense, 1985.

SILVA, José Gomes da. Buraco negro: a reforma agrária na constituinte de 1987/88. Rio de Janeiro: Ed. Paz e Terra, 1988.

SOUZA, Jessé. A tolice da inteligência brasileira: ou como o país se deixa manipular pela elite. São Paulo: LeYa, 2015. 